\title{
Gram Negative Extended Spectrum Beta-Lactamase Producing Bacteria Prevalence in Jouf Region Tertiary Care Hospital, Saudi Arabia
}

\author{
Javid Iqbal Rather ${ }^{1}$, Zahoor Mohi ud din ${ }^{2}$ (D) Farkhanda N. Syed ${ }^{2}$ (D), \\ Mir Haris ${ }^{2}$, Mudasar Nabi ${ }^{3}$ (D) Ambreena Farooq ${ }^{3}$, Bilal Ahmad Tantry ${ }^{4 *}$ (D), \\ Abdul Hafeez Muhammed ${ }^{4}$ and Shaik Rahiman ${ }^{5}$ \\ ${ }^{1}$ Department of Physiology, GMC Srinagar, Kashmir, Jammu and Kashmir, India. \\ ${ }^{2}$ Department of Microbiology, GMC Srinagar, Kashmir, Jammu and Kashmir, India. \\ ${ }^{3}$ Department of Clinical Biochemistry, University of Kashmir, Srinagar, Kashmir, Jammu and Kashmir, India. \\ ${ }^{4}$ Department of Microbiology, Jouf University, College of Medicine, Saudi Arabia. \\ ${ }^{5}$ Department of Biochemistry, Jouf University, College of Medicine, Saudi Arabia.
}

\begin{abstract}
Extended Spectrum beta lactamase producing pathogens are reported in many clinical samples and pose an emerging threat health. To find the prevalence of ESBL producing Enterobactriacea pathogens isolated from inpatients (Medical and Surgical Wards; Hospital stay $>72 \mathrm{~h}$ ) admitted to Prince, Mutib, Hospital Sakaka, Jouf. A total of 1043 Enterobactriacea were isolated during April 2015 to October 2016 study period. Vitek - 2 compact (biomeriux Leon, France) was used for identification and antimicrobial sensitivity (AST) test. A Total of 115/1043 (11.02\%) ESBL producing pathogens were isolated from urine $15.07 \%(n=242)$, sputum $13.6 \%(n=220)$, wound $10.8 \%(n=287)$ and blood $5.4 \%(n=294)$. Klebsiella pneumonia is most dominant followed by $E$ coli and Proteus miribilis. Cephamycins and carbapenems were found most effective ( $100 \%$ sensitivity) against the pathogens isolated. The aminoglycosides, beta lactams and Fluroquinolnes class of antibiotics, microorganisms have gained the resistance of $20 \%$, $\mathbf{2 2 . 7 \%}, \mathbf{4 0 - 7 0 \%}$ respectively. The infection control measures should be taken seriously and making of effective use of antibiotics is need of hour.
\end{abstract}

Keywords: ESBL, Gram negative bacteria, Antimicrobial sensitivity test, Antibiotics

*Correspondence: btantrey@gmail.com; +916005483362

(Received: January 06, 2021; accepted: February 16, 2021)

Citation: Rather JI, Mohi ud din Z, Syed FN, et al. Gram Negative Extended Spectrum Beta-Lactamase Producing Bacteria Prevalence in Jouf Region Tertiary Care Hospital, Saudi Arabia. J Pure Appl Microbiol. 2021;15(1):421-427. doi:10.22207/ JPAM.15.1.39

(C) The Author(s) 2021. Open Access. This article is distributed under the terms of the Creative Commons Attribution 4.0 International License which permits unrestricted use, sharing, distribution, and reproduction in any medium, provided you give appropriate credit to the original author(s) and the source, provide a link to the Creative Commons license, and indicate if changes were made. 


\section{INTRODUCTION}

The antimicrobial resistance (AMR) is a matter of concern worldwide ${ }^{1}$. Genes encoding beta-lactamase and modification of enzymes in bacteria results in drug resistance ${ }^{2}$.The Enterobacteriaceae carry the genes for resistance to $\beta$ lactams and the $\beta$-lactamase family is divided into four groups: Extended Spectrum $\beta$ Lacatamases (ESBLs), Amp- C type, carbapenmases and Penicillinases. The antimicrobial resistance results in treatment failure, economic loss and a source of resistant genes in bacteria that leads to risk of human health. Among the members of Enterobacteriaceae family (Klebsiella pneumoniae, Pseudomonas aeruginosa, Acinetobacter. Baumannii and Escherichia coli) are known to produce extended-spectrum $\beta$-lacatamse (ESBL) and are a serious threat to human health ${ }^{3} . E$. coli the most important pathogen in community acquired infections and have been studied in detail ${ }^{4}$. ESBL producing pathogens delays suitable antibiotic therapy which in turn leads to longer hospital stay and more economic burden ${ }^{5}$. The resistance to antibiotics causes higher mortality rates in patients. In Asia $70 \%$ of ESBL infections are due to nosocomial acquired. ESBL producing microorganisms are one of the cause of antimicrobial resistance (AMR) ${ }^{6}$. In Europe year, 1980 first case of ESBL was reported and subsequently in USA. Emegence of ESBL present a significant threat to human health, particulary klebsiella and $E$. coli pathogens for which only few antibiotics are available ${ }^{7}$. Countries with low and moderate income are facing problems to overcome or in managing antimicrobial resistance due to lack of surveillance and non-availability of high class microbiology laboratories for diagnosis of pathogens and their antibiograms ${ }^{8}$. The pathogenic microbes belongs to gram positive ${ }^{9}$ and gram negative ${ }^{10}$ have been isolated from wound, blood, sputum and urine samples were reported as antibiotic resistant in nature ${ }^{11}$. The distribution of antimicrobial resistant pathogens changes with time and among the hospitals located in different regions $^{12}$. The prevalence of ESBLs in the middle east and Gulf Cooperation countries (GCC)have been reported ${ }^{13}$. The plasmid encoded genes are largely responsible for the ESBL and they belong to class $A$ and are divided into three genotypes CTX-M, SHV and TEM ${ }^{14}$. This is the first study conducted in Jouf region to explore the prevalence of ESBL producing pathogens among the patients attending the Prince, Mutib, Hospital Sakaka, Jouf, Saudi Arabia.

\section{MATERIALS AND METHODS}

A retrospective study, was conducted during April, 2015 to October 2016 at secondary care 150 bed hospital in rural area of Northern Provence of Saudi Arabia, covering the population of 2.7 million approximately. The total number of 1043 samples (blood, wound, Urine and Sputum) were obtained from patients (Medical and ICUs Wards) attending to the Prince, Muteb, Hospital Sakaka, Jouf, Saudi Arabia..

\section{Bacterial isolation and identification}

Samples (blood, wound, sputum and urine) were streaked on blood agar, Mac Conkey agar, and chocolate agar and were incubated in aerobic condition at $35^{\circ} \mathrm{C}$ growth was observed after $24 \mathrm{hrs}$ and isolates were identified based on morphological and biochemical characteristics using standard procedures of Clinical and Laboratory Standard Institute $(\mathrm{CLSI})^{15}$.

\section{Antimicrobial Susceptibility Test}

The automated Vitek 2 Compac system was used to perform antimicrobial susceptibility tests as per clinical laboratory standards institute (CSLI) protocols ${ }^{15}$. The ESBL isolates were confirmed by the method described by bilal et al., $2018^{29}$ and the following American type culture collection strains Klebseilla pneumoniae ATCC 700603, Proteus mirabilis ATCC BAA- 856 and E. coli ATCC 25922 were used as controls.

The vitek 2 antimicrobial susceptibility test (AST) card is composed of Amikacin (30 $\mu \mathrm{g})$ Gentamicin $(10 \mu \mathrm{g})$, Ertapenem $(10 \mu \mathrm{g})$, Imipenem $(10 \mu \mathrm{g})$, Meropenem $(10 \mu \mathrm{g})$, Cephalothin $(30 \mu \mathrm{g})$, Cefuroxime $(30 \mu \mathrm{g})$, Cefoxitin $(30 \mu \mathrm{g})$, Ceftazidime $(30 \mu \mathrm{g})$, Ceftriaxone $(30 \mu \mathrm{g})$, Cefepime $(30 \mu \mathrm{g})$, Aztreonam (30 $\mu \mathrm{g})$, Ampicillin $(10 \mu \mathrm{g})$, AmoxicillinClavulanate $(20+10 \mu \mathrm{g})$, Piperacillin-Tazobactam $(100 / 10 \mu \mathrm{g})$, Colistin $(10 \mu \mathrm{g})$, TrimethoprimSulfamethoxazole $(1.25+23.75 \mu \mathrm{g})$ Nitrofurantoin $(300 \mu \mathrm{g})$, Ciprofloxacin $(5 \mu \mathrm{g})$, Levofloxacin $(5 \mu \mathrm{g})$, Tigecycline $(15 \mu \mathrm{g})$.

Statistical analysis

The study data was analyzed with the aid of SPSS V.17 (statistical package for the social sciences) software. 


\section{RESULTS}

Demographic and Distribution of Isolates

The 1.5 year retrospective study revealed that 1043 patients were admitted in Prince Muteb hospital during April 2015- October 2016.The microorganisms were isolated from various clinical samples urine $15.07 \%(n=242)$, sputum $13.6 \%$ $(n=220)$, wound $10.8 \%(n=287)$ and blood $5.4 \%$ $(n=294)$ (Fig. 1 ). A total of $115 / 1043(11.02 \%)$ pathogens were isolated that are ESBL producing Enterobacteriacea and were obtained from 73 (63.4\%) males and 42 (36.5\%)females and amongst the most predominant ESBL pathogen was Klebsiella pneumoniae $36.5 \%(n=42)$ followed by E. coli $34.7 \%(n=40)$ and Proteus $28.6 \%(n=33)$. It is worth to mention that 73 patients (63.4\%) were non Saudis and 94 (81.7\%) were remained in hospital for more than 3 days. The demographic profile of population is Shown in Table 1.

Antimicrobial resistance of ESBL producing Enterobacteriacea

A high rate of resistance was observed in Klebsiella pneumonia isolated from blood, urine, wound and pus against the antimicrobials. Among the aminoglycosides the resistance rate was found as gentamycin (60-89\%) and Amakacin (20-28\%). Cephaloprorins: ceftazidime (100\%), cefotaxime (100\%), cefepime (98\%) and Fluroquinolones: levofloxacin (40-67.7\%), ciprofloxacin (40-83\%) and Sulpha drug: trimethoprim/sulfamethoxazole (50\%)(Fig. 2) Proteus mirabilis showed the resistance pattern towards aminoglycosides as gentamycin (79-89\%) and amakacin (20-43\%), Cephaloprorins: ceftazidime (100\%), cefotaxime

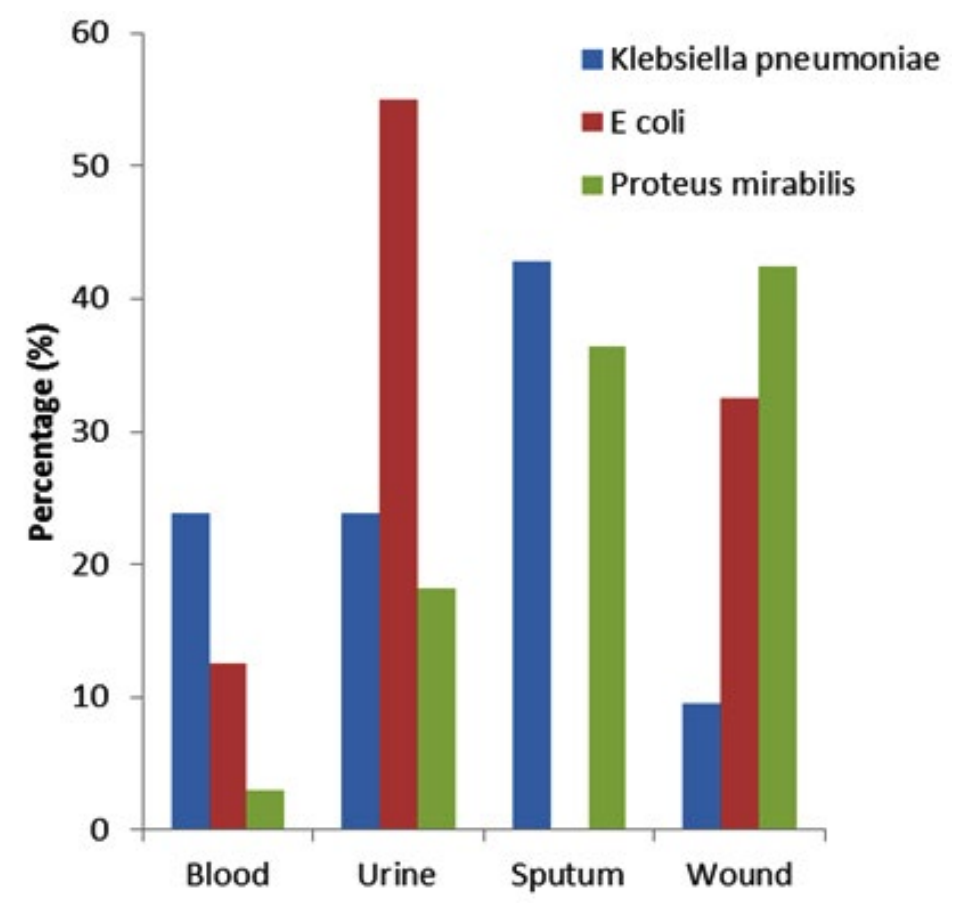

Fig. 1. Percentage of ESBL producing Enterobactericea.

Table 1. The prevalence of ESBL producing Enterobactericea in the study subjects

\begin{tabular}{|c|c|c|c|c|c|}
\hline \multirow[t]{2}{*}{ Gender } & \multirow[t]{2}{*}{ Total No. (\%) } & \multicolumn{2}{|c|}{ Nationality } & \multicolumn{2}{|c|}{ Hospital stay } \\
\hline & & Saudi & Non-Saudi & $<3$ days & $>3$ days \\
\hline Male & $73(63.4)$ & 26 & 47 & 09 & 64 \\
\hline Female & $42(36.5)$ & 16 & 26 & 12 & 30 \\
\hline Total & 115 & $42(36.5 \%)$ & $73(63.4 \%)$ & $21(18.2 \%)$ & $94(81.7 \%)$ \\
\hline
\end{tabular}


(100\%), cefepime (98\%) and Fluroquinolones: levofloxacin (67.7-71\%), ciprofloxacin (40-83\%) and Sulpha drug: trimethoprim/sulfamethoxazole (100\%) and for tigecycline resistance (67-71\%)(Fig. 3). The ESBI producing $E$ Coli the rate of resistance pattern towards antibiotics was lower as compared to Klebsiella pneumonia and Proteus mirabilis. The aminoglycosides were found resistant (18-27\% ).
Cephaloprorins: ceftazidime (100\%), cefotaxime (100\%), cefepime (68\%) and Fluroquinolones: levofloxacin (18\%), ciprofloxacin (60\%) and Sulpha drug: trimethoprim/sulfamethoxazole $(22.7 \%)$ and for tigecycline resistance (13.6\%).(Fig. 4)

The cephamycins (Cefoxitin), AmoxicillinClavulanate, Piperacillin-Tazobactam and carbapenems (Meropenem, Ertapenem and

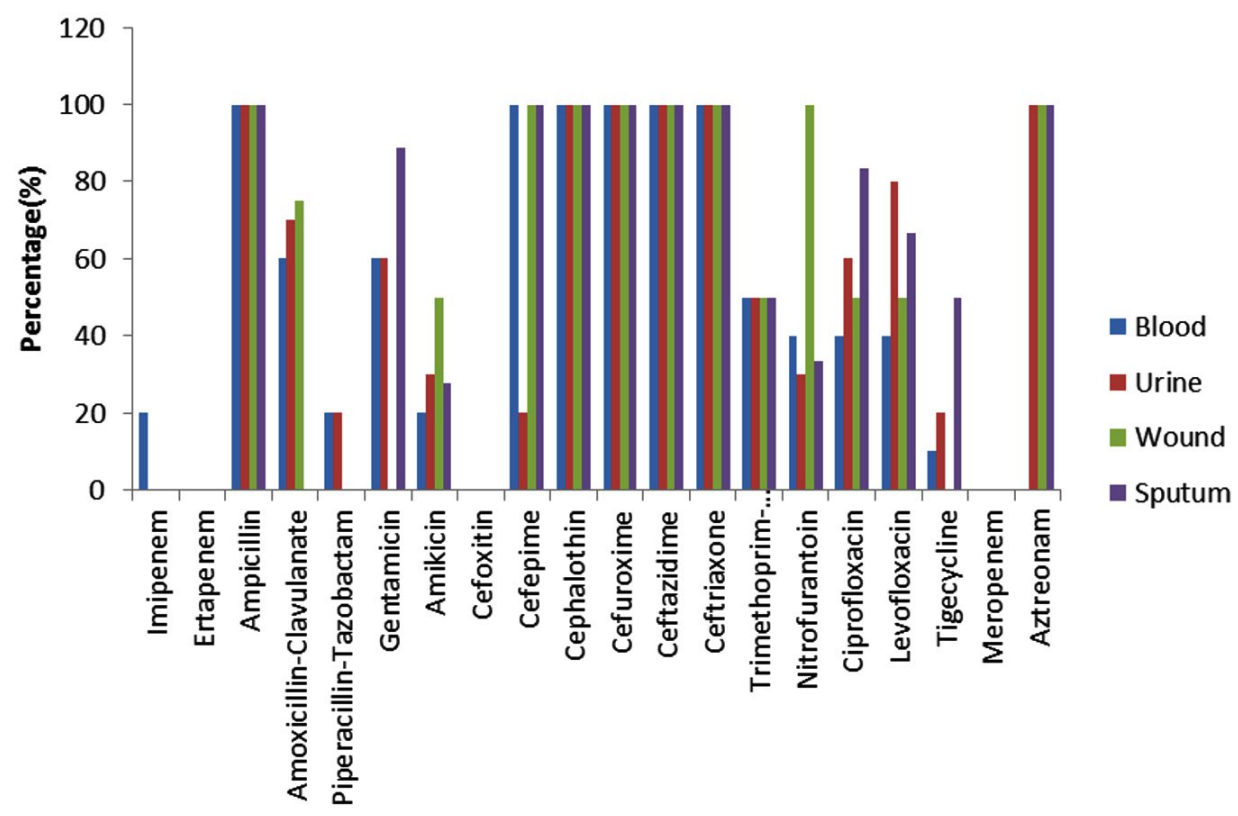

Fig. 2. Antibiotic resistance pattern of ESBL producing Klebsiella pneumoniae

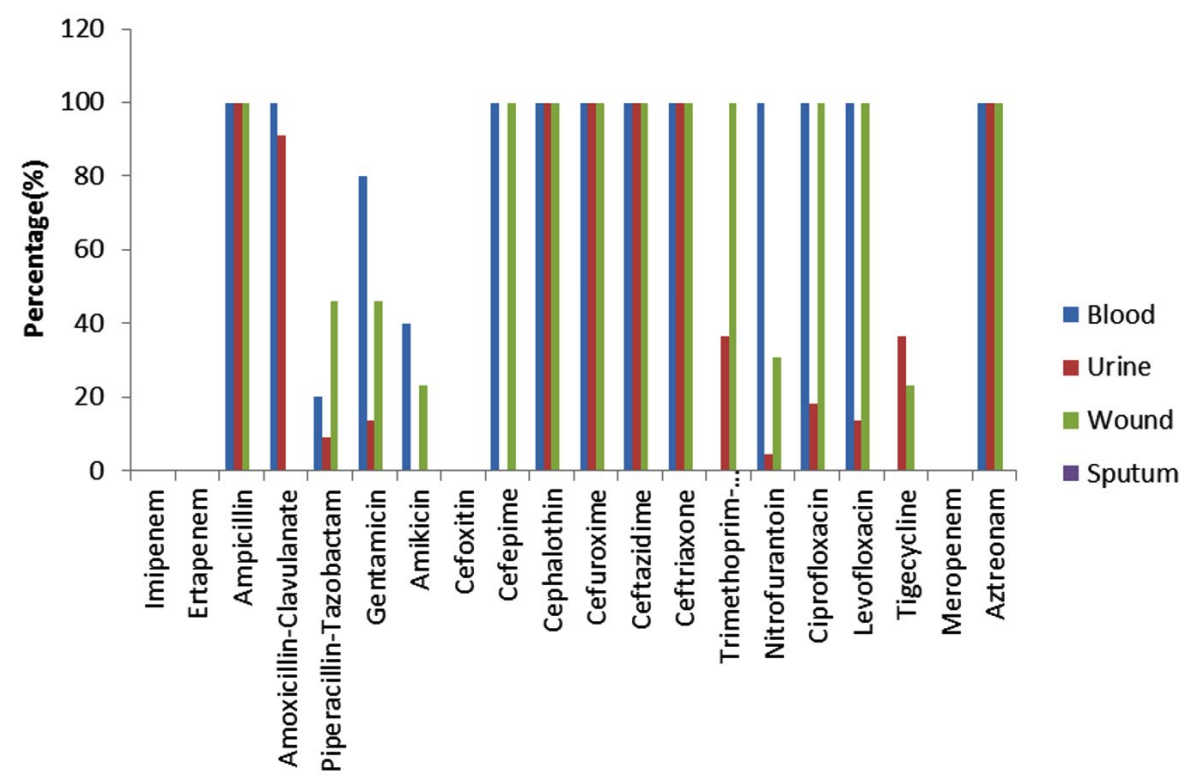

Fig. 3. Antibiotic resistance pattern of ESBL producing E.Coli 


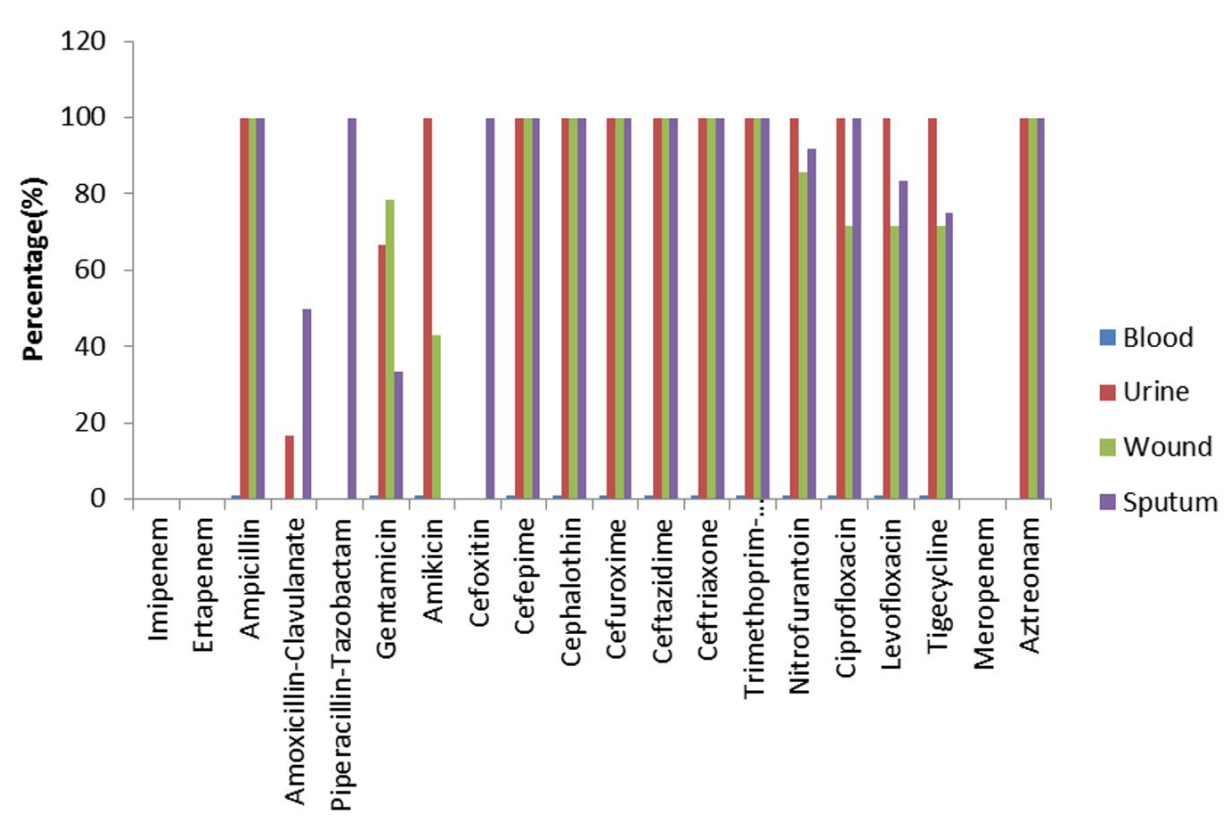

Fig. 4. Antibiotic resistance pattern of ESBL producing proteus mirabilis

imepenem) were effectively sensitive against all the isolated ESBL producers. ESBL producing Klebsiella pneumonia strains from sputum showed an intermediate susesptebility of $11 \%$ towards Cefoxitin. We did not find any strain resistant to meropenem and Eratapenem. However, Klebsiella pneumonia isolated from blood samples showed $20 \%$ resistance to imepenem.

\section{DISCUSSION}

In this study 115 ESBL producing Enterobacteriaceae were found among inpatients (Medical and ICUs wards) in Prince Muteb Hospital, Jouf, Saudi Arabia. Our results revealed ESBL producing $E$. coli and klebseilla pneumoniae is significantly higher than previous studies reported form Abha, Riayadh, Dammam and Al Khobar, Saudi Arabia ${ }^{16-18}$. The ESBL producing proteus mirabilisin our study subjects were found $36.8 \%$ which is higher as compared to other studies ${ }^{18}$.

In Europe, Turkey, Russia and Poland the prevalence of ESBLs was found $2-47 \%{ }^{19}$, from the southern America (Brazil) 60\% ${ }^{20,21}$. In Asia, ESBL producing Enterobacteriaceae (E. coli) $5 \%$ in Japan, $57 \%$ in China and Thailand were reported. In Pakisthan the prevelance was reported as highest $(73 \%)^{22}$. In Middle East, Kuwait, and UAE the ESBLs were reported $25 \%$ and $36 \%$ respectively ${ }^{23,24}$. In our study $115 / 1043$ were ESBL producing Enterobacteriaceae (K. pneumoniae, $E$. coli and P.mirabilis). To our knowledge, this is the first study conducted in the northern region of Saudi Arabia to explore the ESBLs prevalence and its susceptibility pattern. The frequency of ESBLs in E. coli K. pneumoniae and P. mirabilisis 36.5\%, $34.7 \%$ and $28.6 \%$ respectively. From Al Khobar, the E. coli and K. pneumoniae was reported $10.3 \%$ and $12.3 \%{ }^{25}$. This variation may be due to differences in the number of isolates (either Tertiary care hospital or community based).

Further, in our study we did not find any strains resistance to cephamycins and carbapenems. The efficiency of these drug classes has been attributed to the stability of beta lactamases. Hence, cephamycins and carbapenems are the choice of drugs for treating the patients with infections caused by ESBL producing Enterobacteriaceae. The ESBL producing $P$. mirabilis, E. coli and $K$. pneumoniae, isolates in our study are resistance to all the generations (I- IV) of cephalosporins in hospitalized patients. Whereas, Menyfah et al.,(2018) reported that, 
ampicillin, Trimethoprim-Sulfamethoxazole showed highest resistance to $E$. coli isolates in Riyadh Saudi Arabia 25 .

Aminoglycosides, Nitrofurantoin and sulpha drugs were $70 \%$ resistance to clinical isolates in our study. Whereas, in Norway, E. coli and $K$. pneumoniae showed high resistance to aminoglycoside due to the presence of modified enzymes $A A C(6)-1 b^{26}$. Higher rate of resistance against ceprofloxin, levofloxacin, ceftriaxone, cepfepem, Tigylcyline, Azetranoam and Ampicillin in community is probably due to over use, misuse or self-medications.

Previous studies has shown that, the antibiotic resistance against the Ceftriaxone, Cefuroxime, Ciprofloxacin, Ampicillin for ESBL producing pathogens ${ }^{17,27,28}$. However, our study also revealed that, the antibiotic resistance against Levofloxacin, Cefepime and Aztreonam. This ineffectivity against the Gram negative bacteria occur due to the mutations and spread of ESBLs with in the Enterobacteriaceae family and extensive use of these antibiotics for prophylaxis.

\section{ACKNOWLEDGMENTS}

We would like to express our heartfelt thanks to Mr. Shameem Khan for providing assistance on methods (detection of ESBL isolates). We would like to thank the microbiology department of Muteb Hospital for providing access to data files of the test reports.

\section{CONFLICT OF INTEREST}

The authors declare that there is no conflict of interest.

\section{AUTHORS' CONTRIBUTION}

$\mathrm{BA}, \mathrm{SR} \& \mathrm{MAH}$ designed the restrospective study plan. JI, Z, FNS collected the data of the study and later double checked it. $\mathrm{M}$ and $\mathrm{A}$ analyzed the data, drafted the manuscript, compiled information from the literature, and designed the Figures and tables. M, A, BA, SR \& MAH wrote the manuscript. All authors read and approved the manuscript.

\section{FUNDING}

None.

\section{DATA AVAILABILITY}

All datasets generated or analyzed during this study are included in the manuscript

\section{ETHICS STATEMENT}

Not applicable.

\section{REFERENCES}

1. Holloway K, Mathai E, Gray A, Use CBSoA, Group RiRCSP. Surveillance of antimicrobial resistance in resource-constrained settings-experience from five pilot projects. Trop Med Int Health. 2011;16(3):368374. doi: 10.1111/j.1365-3156.2010.02696.x

2. Zhao W-H, Hu Z-Q. $\beta$-lactamases identified in clinical isolates of Pseudomonas aeruginosa. Crit Rev Microbiol. 2010;36(3):245-258. doi: 10.3109/1040841X.2010.481763

3. Liu Z, Li W, Wang J, et al. Identification and characterization of the first Escherichia coli strain carrying NDM-1 gene in China. PloS ONE. 2013;8(6):e66666. doi: 10.1371/journal.pone.0066666

4. Hafeez R, Aslam M, Mir F, Tahir M, Javaid I, Ajmal AN. Frequency of extended spectrum beta lactamase producing gram negative bacilli among clinical isolates. Biomedica. 2009;25(2):112-115.

5. Ndir A, Diop A, Ka R, et al. Infections caused by extended-spectrum beta-lactamases producing Enterobacteriaceae: clinical and economic impact in patients hospitalized in 2 teaching hospitals in Dakar, Senegal. Antimicrob Resist Infect Control. 2016;5(1):13. doi: 10.1186/s13756-016-0114-7

6. Pitout JD. Infections with extended-spectrum $\beta$-lactamase-producing Enterobacteriaceae. Drugs. 2010;70(3):313-333. doi: 10.2165/11533040000000000-00000

7. Talbot GH, Bradley J, Edwards Jr JE, Gilbert D, Scheld $M$, Bartlett JG. Bad bugs need drugs: an update on the development pipeline from the Antimicrobial Availability Task Force of the Infectious Diseases Society of America. Clin Infect Dis. 2006;42(5):657-668. doi: $10.1086 / 499819$

8. Paterson DL. The role of antimicrobial management programs in optimizing antibiotic prescribing within hospitals. Clin Infect Dis. 2006;42(Suppl 2):S90-S95. doi: $10.1086 / 499407$

9. Mordi R, Momoh M. Incidence of Proteus species in wound infections and their sensitivity pattern in the University of Benin Teaching Hospital. African Journal of Biotechnology. 2009;8(5).

10. Hanson ND, Moland ES, Hong S, Propst K, Novak DJ, Cavalieri SJ. Surveillance of community-based reservoirs reveals the presence of CTX-M, imported $\mathrm{AmpC}$, and OXA-30 $\beta$-lactamases in urine isolates of Klebsiella pneumoniae and Escherichia coli in a US community. Antimicrob Agents Chemother. 2008;52(10):3814-3816. doi: 10.1128/AAC.00877-08

11. Kanoksil M, Jatapai A, Peacock SJ, Limmathurotsakul D. Correction: Epidemiology, Microbiology and Mortality Associated with Community-Acquired Bacteremia in 
Northeast Thailand: A Multicenter Surveillance Study. PLOS ONE. 2013;8(10). doi: 10.1371/annotation/ e199ebcc-0bc1-4be1-ad91-ad2a8c0c9382

12. Edmond MB, Wallace SE, McClish DK, Pfaller MA, Jones RN, Wenzel RP. Nosocomial bloodstream infections in United States hospitals: a three-year analysis. Clin Infect Dis. 1999;29(2):239-244. doi: 10.1086/520192

13. Zowawi HM, Balkhy HH, Walsh TR, Paterson DL. $\beta$-Lactamase production in key gram-negative pathogen isolates from the Arabian Peninsula. Clin Microbiol Rev. 2013;26(3):361-380. doi: 10.1128/ CMR.00096-12

14. Malloy AM, Campos JM. Extended-spectrum betalactamases: a brief clinical update. The Pediatr Infect Dis J. 2011;30(12):1092-1093. doi: 10.1097/ INF.0b013e31823c0e9d

15. Wayne P. Clinical and laboratory standards institute. Performance standards for antimicrobial susceptibility testing. 2011.

16. Bilal NE, Gedebou M. Clinical and community strains of Klebsiella pneumoniae: multiple and increasing rates of antibiotic resistance in Abha, Saudi Arabia. British Journal of Biomedical Science. 2000;57(3):185.

17. Kader AA, Kumar A. Prevalence and antimicrobial susceptibility of extended-spectrum beta-lactamaseproducing Escherichia coli and Klebsiella pneumoniae in a general hospital. Ann Saudi Med. 2005;25(3):239242. doi: 10.5144/0256-4947.2005.239

18. El-Khizzi NA, Bakheshwain SM. Prevalence of extendedspectrum beta-lactamases among Enterobacteriaceae isolated from blood culture in a tertiary care hospital. Saudi Med J. 2006;27(1):37-40.

19. Goossens H, Group MS. MYSTIC program: summary of European data from 1997 to 2000. Diagn Microbiol Infect Dis. 2001;41(4):183-189. doi: 10.1016/S07328893(01)00320-0

20. Gupta A, Della-Latta P, Todd B, et al. Outbreak of extended-spectrum beta-lactamase-producing Klebsiella pneumoniae in a neonatal intensive care unit linked to artificial nails. Infect Control Hosp Epidemiol. 2004;25(3):210-215. doi: 10.1086/502380

21. Pfaller MA, Jones RN, Doern GV, Group VARS. Multicenter evaluation of the antimicrobial activity for six broad-spectrum $\beta$-lactams in Venezuela using the Etest method. Diagn Microbiol Infect
Dis. $1998 ; 30(1): 45-52$. doi: $10.1016 /$ S07328893(97)00158-2

22. Artide O. Prevalence of extended-spectrum $\beta$-lactamases in nosocomial and outpatients (ambulatory). Pak J Med Sci. 2003;19(3):187-191.

23. Al-Zarouni M, Senok A, Rashid F, Al-Jesmi SM, Panigrahi D. Prevalence and antimicrobial susceptibility pattern of extended-spectrum beta-lactamaseproducing Enterobacteriaceae in the United Arab Emirates. Med Princ Pract. 2008;17(1):32-36. doi: 10.1159/000109587

24. Jamal W, Rotimi V, Khodakhast F, Saleem R, Pazhoor A, Al Hashim G. Prevalence of extended-spectrum betalactamases in Enterobacteriaceae, Pseudomonas and Stenotrophomonas as determined by the VITEK 2 and E test systems in a Kuwait teaching hospital. Med Princ Pract. 2005;14(5):325-331. doi: 10.1159/000086930

25. Alanazi MQ, Alqahtani FY, Aleanizy FS. An evaluation of $E$. coli in urinary tract infection in emergency department at KAMC in Riyadh, Saudi Arabia: retrospective study. Ann Clin Microbiol Antimicrob. 2018;17(1):3. doi: 10.1186/s12941-018-0255-z

26. Haldorsen BC, Simonsen GS, Sundsfjord A, Samuelsen $O$. Increased prevalence of aminoglycoside resistance in clinical isolates of Escherichia coli and Klebsiella spp. in Norway is associated with the acquisition of AAC (3)-II and AAC (6')-Ib. Diagn Microbiol Infect Dis. 2014;78(1):66-69. doi: 10.1016/j. diagmicrobio.2013.10.001

27. Rahal JJ, Urban C, Horn D, et al. Class restriction of cephalosporin use to control total cephalosporin resistance in nosocomial Klebsiella. JAMA. 1998;280(14):1233-1237. doi: 10.1001/ jama.280.14.1233

28. Rodriguez-Bano J, Navarro M, Romero L, et al. Riskfactors for emerging bloodstream infections caused by extended-spectrum $\beta$-lactamase-producing Escherichia coli. Clin Microbiol Infect. 2008;14(2):180183. doi: 10.1111/j.1469-0691.2007.01884.x

29. Tantry BA, Mohammed AH, Rahiman S, Tantry MN. Detection of Extended-Spectrum $\beta$-lactamases Production by Escherichia coli: A Phenotypic Comparative Study. J Pure Appl Microbiol. 2018;12(4):2245-2252. doi: 10.22207/JPAM.12.4.64 